\title{
Procjena kvalitete edukacije medicinskih sestara u pripremi trudnice za porod Assessment of the Quality Education of Nurses in Preparing Pregnant Women for Childbirth
}

\author{
Jadranka Ristić', Vesna Turuk², Ružica Mrkonjić3 \\ ${ }^{1}$ Klinika za ginekologiju i porodništvo, Klinička bolnica "Sveti Duh", Zagreb, Croatia \\ 'Department of Obstetrics and Gynecology, University Hospital "Sveti Duh", Zagreb, Croatia \\ ${ }^{2}$ Zdravstveno veleučilište Zagreb, Studij sestrinstva, Zagreb, Croatia \\ ${ }^{2}$ Health Studies Zagreb, School of Nursing, Zagreb, Croatia \\ ${ }^{3}$ Zavod za kardijalnu i transplantacijsku kirurgiju, Klinička bolnica Dubrava, Zagreb, Croatia \\ ${ }^{3}$ Department for Cardiac and Transplantation Surgery, University Hospital Dubrava, Zagreb, Croatia
}

\section{Sažetak}

Uvod: Priprema trudnica za porod postiže se organizacijom interdisciplinarnih stručnih tečajeva pripreme trudnica za porod i roditeljsku funkciju koji su dostupni svim trudnicama u sustavu zdravstvene zaštite Republike Hrvatske.

Cilj: Analizirati prolaze li sve trudnice tečaj, neovisno o tome jesu li prošle trudnički tečaj, i koliko je tečaj bitan za smanjenje broja komplikacija u tijeku i nakon poroda.

Metode i ispitanici: Istraživanje je provedeno u razdoblju od kolovoza do studenog 2014. godine na Klinici za ginekologiju i porodništvo Kliničke bolnice "Sveti Duh". U istraživanje je uključeno 150 babinjača koje su se liječile na odjelu drugi dan nakon poroda.

Rezultati: Trudnički je tečaj pohađalo samo pola ispitanih babinjača, veliki postotak trudnica pripremu za porod prolazi uz internet. Problema sa skrbi za novorođenče ima preko pola ispitanica, uz to, i educiranost medicinske sestre koja je član tima za provođenje trudničkog tečaja, više od 50\% ispitanih babinjača ocjenjuje kao nedostatnu.

Zaključak: Iz prikupljenih podataka može se zaključiti da se u prenatalnu zaštitu moraju više uključiti medinske sestre primarne zdravstvene zaštite s preporukom obveznog tečaja za sve trudnice, ali je vrlo važno i povečanje stupnja edukacije zdravstvenih djelatnika koji sudjeluju u pripremi trudnica za porod, kako bi trudnice bile zadovoljne i spremne za sve postupke koji ih očekuju u porodu i nakon njega.

Ključne riječi: babinjača • stručni tečaj pripreme trudnice za porod • medicinska sestra

Kratki naslov: Edukacija medicinskih sestara

\begin{abstract}
Introduction: Preparing pregnant women for childbirth is achieved by organizing courses which are available to all pregnant women in the health care system of the Republic of Croatia.
\end{abstract}

Objective: Bearing in mind the importance of preparing pregnant women for maternity and childbirth and availability of courses in the health care system in Croatia research was undertaken to ascertain whether all pregnant women took courses preparation for childbirth, and to assess whether there were differences in the occurrence of complications in prepared and in unprepared women. In addition puerperas rated education of the nurses in the team wich led the course.

Methods and patients: The study was conducted in the period from August to November 2014 at the Department of Obstetrics and Gynecology at University Hospital "Holy Spirit". The study included 150 puerpera the second day after birth.

Results: Only half of the respondent's attended pregnancy course. A large percentage of pregnant women prepare for birth using information on the internet. More than half of the puerperas had problems with caring for newborn babies. Educational level of the nurses was scored as insufficient in more than half of the puerperas.

Conclusion: Thus, we can conclude that the prenatal care should include more primary health interventions with a recommendation of mandatory course for all pregnant women. It is also very important to get regular education teams that participate in the preparation for childbirth, to increase the satisfaction and prepereness for childbirth and early child care.

Keywords: puerpera $\bullet$ pregnancy course $\bullet$ nurse

Running head: Education of nurses

Autor za korespondenciju/Corresponding author: Jadranka Ristić, Department of Obstetrics and Gynecology, University Hospital "Sveti Duh", Zagreb, Croatia • Tel: +385-91 3712 479 • e-mail: jadra.risti@gmail.com

\section{Uvod / Introduction}

Priprema trudnica za porod postiže se organizacijom interdisciplinarnih stučnih tečajeva pripreme trudnice za porod koji trudnica može početi polaziti od četvrtog mjeseca trudnoće, kako bi se postupno uvodila u određene oblike fizičke pripreme prema njenom trenutnom stanju.
Stručni tečajevi sadrže nastavne programe ginekologa, medicinske sestre, primalje, fizioterapeuta, pedijatra i psihologa s određenim temama o trudnoći, porodu i poslijeporodnom dobu. Trajanje je tečaja mjesec dana (ukupno 12 sati). U prva četiri sata specijalist ginekologije objašnjava fiziolo- 
giju poroda i upoznaje trudnice s tijekom poroda i mogućnostima analgezije. Od četvrtog do osmog sata asistentica primalja i medicinska sestra objašnjavaju rodilji proceduru samog poroda i uspostavljaju pozitivnu komunikaciju. U posljednja četiri sata trudnica dobiva informacije od specijalista neonatologije o važnosti dojenja i postupanju s novorođenčetom. Kroz sva tri dolaska trudnica se također susreće s fizioterapeutom koji educira trudnicu o tehnikama disanja i tehnikama relaksacije [1].

U Republici Hrvatskoj tečajevi su dostupni svim trudnicama u sklopu obavezne zdravstvene zaštite. U timove su uključeni stručnjaci različitih specijalnosti sa završenim dodiplomskim studijem [1].

Psihička priprema znači osloboditi trudnicu od straha detaljnim objašnjenjem stanja koja se mogu očekivati. To obuhvaća upoznavanje s fiziologijom trudnoće i poroda, a vrlo je važna i emocionalna stabilnost i zadovoljstvo trudnice vlastitim životom [2]. S obzirom da stres može ometati proces porođaja, razumno je očekivati da će smanjenje stresa dovesti do pojednostavljenja procesa rađanja [3]. Ipak, svaki čovjek na podsvjesnoj razini pamti razdoblje trudnoće i porođaja, te sve intervencije koje se dogode $u$ tijeku poroda mogu utjecati na čovjekov život [4].

\section{Cilj / Aim}

Cilj je rada analizirati u kojem obimu trudnice polaze tečaj pripreme za porod i roditeljsku funkciju i koliko pohađanje tečaja utječe na smanjenje pojavnosti komplikacija u tijeku i nakon porođaja.

TABLiCA [1] Demografski podaci ukupnog broja ispitanica

\begin{tabular}{lcc}
\hline \multirow{2}{*}{ Karakteristike } & \multicolumn{2}{c}{ Ukupno [N=150] } \\
\cline { 2 - 3 } & frekvencija & postotak \\
\hline Dob & 3 & 2 \\
$<20$ & 17 & 11 \\
$21-25$ & 49 & 33 \\
$26-30$ & 59 & 39 \\
$31-35$ & 19 & 13 \\
$36-40$ & 3 & 2 \\
$>40$ & & \\
\hline Stručna sprema & 69 & 46 \\
SSS & 24 & 16 \\
VŠS & 57 & 38 \\
VSS & & \\
\hline Broj poroda & 72 & 48 \\
1 & 53 & 35 \\
2 & 17 & 11 \\
3 & 8 & 5 \\
4 & & \\
\hline Metoda poroda & 114 & 76 \\
vaginalni porod & 36 & 24 \\
carski red & & \\
\hline Broj ispitanica koje su prošle & 80 & 56 \\
trudnički tečaj & 64 & 56 \\
ispitanice koje su rodile vaginalno & 16 & 44 \\
ispitanice koje su rodile carskim & & \\
rezom & & \\
\hline
\end{tabular}

\section{Materijali i ispitanici / Materials and participants}

Istraživanje je provedeno u periodu od kolovoza do studenog 2014. godine na Klinici za ginekologiju i porodništvo Kliničke bolnice "Sveti Duh". U istraživanje je uključeno 150 ispitanica koje su ležale na odjelu drugi dan nakon poroda. Od ukupnog broja ispitanica njih 36 rodilo je carskim rezom, a 114 vaginalnim porodom.

Za istraživanje je konstruiran originalni upitnik. Istim se istražuje stupanj pripremljenosti za tijek poroda, stavovi trudnica u odnosu na dojenje, te razlike u pojavnosti komplikacija u skupini trudnica koje su pohađale i one koje nisu pohađale trudnički tečaj. Prvi dio upitnika uključuje demografske podatke o ispitanicama, dob, razinu obrazovanja, odnosno stručnu spremu i način poroda [Tablica 2].

Drugi dio upitnika sadrži pitanja i odgovore kojima se procjenjuju stavovi babinjača o provedenom trudničkom tečaju i stupnju pripremljenosti za skrb o novorođenčetu.

Odgovori na sve tvrdnje prikazani su na Likertovoj mjernoj ljestvici samoprocjene od 1 do 5 , pri čemu 1 označavauopće se ne slažem, 2-uglavnom se slažem, 3-niti se slažem niti se ne slažem, 4-uglavnom se slažem, 5-u potpunosti se slažem. Drugi dio upitnika sadrži 10 pitanja. Sadržaj upitnika prikazan je u tablici [3].

TABLICA [2] Demografski podaci

\begin{tabular}{ll}
\hline 1) Koliko imate godina? \\
$\begin{array}{ll}\text { A) manje od } 20 & \text { D) } 31-35 \\
\text { B) } 21-25 & \text { E) } 36-40 \\
\text { C) } 26-30 & \text { F) više od } 41\end{array}$
\end{tabular}

\section{2) Stručna sprema}
A) SSS
B) VŠS
C) VSS

3) Koliko ste poroda sveukupno imali?
A) 1
B) 2
D) 4
C) 3

4) Je li porod bio vaginalni ili carskim rezom?
A) vaginalni porod
B) porod carskim rezom

TABLICA [3] Procjena stavova i pripremljenosti babinjača nakon provedenog trudničkog tečaja

5) Jeste li polazili tečaj pripreme trudnice za porod?

A) da

6) Informacije koje ste dobili na tečaju pripreme trudnice za porod bile su korisne i pomogle su Vam pri samom porođaju i nakon porođaja.

1-uopće se ne slažem - 5- u potpunosti se slažem

$\begin{array}{lllll}1 & 2 & 3 & 4 & 5\end{array}$ 


7) Informacije koje ste dobili na tečaju pripreme trudnice
za porod bile su korisne i pomogle su Vam pri dojenju
novorođenčeta.

1-uopće se ne slažem - 5- u potpunosti se slažem

$\begin{array}{lllll}1 & 2 & 3 & 4 & 5\end{array}$

8) Informacije koje ste dobili na tečaju pripreme trudnice za porod bile su korisne i pomogle su Vam pri njezi novorođenčeta.

1-uopće se ne slažem - 5- u potpunosti se slažem

$\begin{array}{lllll}1 & 2 & 3 & 4 & 5\end{array}$

9) Medicinska sestra-primalja koja je bila dio tima tečaja pripreme trudnice za porod bila je dovoljno educirana.

1-uopće se ne slažem - 5- u potpunosti se slažem

$\begin{array}{lllll}1 & 2 & 3 & 4 & 5\end{array}$

10) Mislite li da Vas je medicinska sestra-primalja na tečaju pripreme trudnice za porod mogla bolje informirati o nekim situacijama koje Vas očekuju tijekom poroda?

A) da

11) Nakon poroda imali ste poteškoća prilikom stavljanja novorođenčeta u adekvatan položaj za dojenje.

A) da

B) ne

12) Nakon poroda imali ste poteškoća prilikom stavljanja novorođenčeta na prsa (npr. je li Vam je dijete dobro obuhvatilo bradavicu).

\section{A) da}

B) ne

13) Jeste li se snašli u prematanju novorođenčeta?

A) da

B) ne

14) Jeste li uspješno prvi put premotali novorođenče?

A)da

B)ne

Treći dio upitnika odnosio se na ispitanice koje nisu prošle trudnički tečaj, a imao je za cilj procijeniti na koji način su se ispitanice informirale o porodu, te smatraju li da bi bile bolje pripremljene da su pohađale trudnički tečaj.

TABLICA [4] Procjena metode informiranja o porodu, te subjektivna procjena ispitanica o potrebi pohađanja trudničkih tečajeva

15) Nedostajala Vam je priprema za porod putem tečaja pripreme trudnice za porod.

1-uopće se ne slažem - 5-u potpunosti se slažem

$\begin{array}{lllll}1 & 2 & 3 & 4 & 5\end{array}$

16) Na koji ste se način pripremali za porod?

A) mediji (TV,radio)

B) internet

C) knjige, priručnici, katalozi

D) nešto drugo
Svi rezultati su deskriptivno i tabelarno objašnjeni uz prikaz distribucija frekvencije grafikonima izrađenim u MS-Officeu 2007. Razlike u vrijednostima između grupa testirane su X2 i t-testom, sa stupnjem značajnosti od 95\% ( $p<0,05)$.

\section{Rezultati/ Results}

Od ukupno 150 ispitanica, mlađe od 20 godina bile su 3 ispitanice (2\%), 17 ih je iz starosne skupine od 21 do 25 godina (11\%), njih 49 (33\%) ih je bilo staro između 26 i 30 godina, iz dobne skupine od 31 do 35 godina bilo je 59 ispitanica (39\%), 19 ispitanica bilo je u dobi od36 do 40 godina (13\%), a tri su ispitanice bile starije od 40 godina (2\%).

Najveći broj ispitanica, njih 69 (46\%) ima završen srednji stupanj obrazovanja, 24 (16\%) viši stupanj obrazovanja, a njih 57 (38\%) visoki stupanj obrazovanja.

Najveći broj ispitanica , njih 72 (48\%) rodilo je prvi put, 53 (35\%) rađale su drugiput, 17 (11\%) trećiput, a 8 (5\%) ispitanica rađa četvrti put.

Od ukupnog broja ispitanica njih 114 (76\%) rodilo je vaginalnim putem, a 36 (24\%) carskim rezom.

Trudnički tečaj je pohađalo 80 (53\%) ispitanica, tj. njih 44\% od ukupnog broja ispitanica koje su rodile carskim rezom i $56 \%$ od ukupnog broja ispitanica koje su rodile vaginalnim putem.

\subsection{Rezultati procjene stavova babinjača o korisnosti tečaja za trudnice}

U procjeni pripremljenosti za dojenje i skrb za novorođenče trudnica koje su pohađale tečaj postavljeno je nekoliko pitanja na koja su ispitanice mogle odgovoriti zaokruživanjem tvrdnje kojoj je pridodana brojčana vrijednost.

Na pitanje o ocjeni korisnosti informacija koje su dobile na tečaju za tijek porođaja $26 \%$ ispitanica dalo je najveću ocjenu, $50 \%$ ispitanica uglavnom se slaže, $14 \%$ in je ocijenilo srednjom ocjenom, a 10\% ispitanica korisnost je informacija ocijenilo niskom ocjenom.

Ocjene ispitanica o stupnju educiranosti medicinske sestre koja je bila dio zdravstvenog tima koji je provodio tečaj prikazane su u tablici [5]. Od 80 ispitanica $65 \%$ ih je medicinskoj sestri dalo vrlo dobru ocjenu, $15 \%$ njih je sestru ocijenilo maksimalnom ocjenom, a $5 \%$ je educiranost sestre ocijenilo niskom ocjenom.

U tablici [tablica 6], prikazuju se ocjena korisnosti informacija usvojenih na tečaju.

Na tvrdnju: "Informacije koje ste dobili na tečaju pripreme trudnice za porođaj bile su korisne i pomogle Vam pri dojenju novorođenčeta.", $11 \%$ ispitanica korisnost je informacija ocijenilo maksimalnom ocjenom, najveći broj, njih 45\% dalo je prosječnu ocjenu, a $22 \%$ ispitanica korisnost je informacija ocijenilo lošom ocjenom.

Korisnost informacija koje su dobile na tečaju ispitanice su ocijenile prosječnom ocjenom 3,52 (1-5). Ispitanice koje su rodile carskim rezom korisnost informacija ocijenile su $\mathrm{s}$ 3,69 , a ispitanice koje su rodile vaginalno s ocjenom 3,44. Nije bilo statistički značajne razlike u ocjenama ove dvije skupine ispitanica, $p=0,39$. 
TABLICA [5] Frekvencije odgovora na pojedina pitanja iz Upitnika

\begin{tabular}{|c|c|c|c|c|c|c|c|c|c|c|}
\hline \multirow[t]{3}{*}{ Stavovi o tečaju } & \multicolumn{10}{|c|}{$\begin{array}{l}\text { Likertova ljestvica: } \\
\text { 1- uopće se ne slažem ...5-u potpunosti se slažem. }\end{array}$} \\
\hline & \multicolumn{2}{|c|}{1} & \multicolumn{2}{|c|}{2} & \multicolumn{2}{|c|}{3} & \multicolumn{2}{|c|}{4} & \multicolumn{2}{|c|}{5} \\
\hline & $\mathrm{nN}$ & $\% \%$ & $\mathrm{nN}$ & $\% \%$ & $\mathrm{nN}$ & $\% \%$ & $\mathrm{nN}$ & $\% \%$ & $\mathrm{nN}$ & $\% \%$ \\
\hline $\begin{array}{l}\text { Informacije koje ste dobili na tečaju pripreme trudnice } \\
\text { za porod bile su korisne i pomogle su Vam pri samom } \\
\text { porođaju i nakon porođaja? }\end{array}$ & 2 & 2 & 6 & 8 & 11 & 14 & 40 & 50 & 21 & 26 \\
\hline $\begin{array}{l}\text { Informacije koje ste dobili na tečaju pripreme trudnice } \\
\text { za porod bile su korisne i pomogle su Vam pri dojenju } \\
\text { novorođenčeta? }\end{array}$ & 9 & 11 & 9 & 11 & 17 & 22 & 36 & 45 & 9 & 11 \\
\hline $\begin{array}{l}\text { Informacije koje ste dobili na tečaju pripreme trudnice } \\
\text { za porodbile su korisne i pomogle su Vam pri njezi } \\
\text { novorođenčeta? }\end{array}$ & 1 & 1 & 4 & 5 & 19 & 24 & 45 & 56 & 11 & 14 \\
\hline $\begin{array}{l}\text { Medicinska sestra koja je bila dio tima tečaja pripreme } \\
\text { trudnice za porođaj bila je dovoljno educirana? }\end{array}$ & 1 & 1 & 3 & 4 & 12 & 15 & 52 & 65 & 12 & 15 \\
\hline
\end{tabular}

TABLICA [6] Srednja ocjena korisnosti informacija usvojenih na tečaju

\begin{tabular}{|c|c|c|c|}
\hline \multirow[t]{2}{*}{ Tvrdnja o korisnosti Tečaja } & \multicolumn{2}{|c|}{ Medijan } & \multirow[b]{2}{*}{$\mathbf{p}$} \\
\hline & $\begin{array}{c}\text { ispitanice koje su rodile } \\
\text { vaginalno }\end{array}$ & $\begin{array}{c}\text { ispitanice koje su rodile } \\
\text { carskim rezom }\end{array}$ & \\
\hline Ocjena stupnja korisnosti informacija za tijek porođaja & 3,94 & 4,21 & 0,21 \\
\hline Ocjena stupnja korisnosti informacija za svrhu dojenja & 3,69 & 3,44 & 0,39 \\
\hline Ocjena stupnja korisnosti informacija za svrhe njege novorođenčeta & 4,0 & 3,72 & 0,23 \\
\hline Ocjena educiranosti medicinske sestre & 4,63 & 4,3 & 0,13 \\
\hline
\end{tabular}

Korisnost informacija s tečaja za stjecanje vještina njege novorođenčeta ispitanice su ocijenile prosječnom ocjenom 3,72 (2-5). Ispitanice koje su rodile carskim rezom dale su ocjenu 4,0, a ispitanice koje su rodile vaginalno 3,72. Nije bilo statistički značajne razlike između ove dvije skupine ispitanica, $p=0,23$.

Educiranost medicinske sestre ispitanice su ocijenile prosječnom ocjenom 4,37 (2-5). Ispitanice koje su rodile carskim rezom dale su ocjenu 4,63, a ispitanice koje su rodile vaginalno 4,30 . Nije bilo statistički značajne razlike između ove dvije skupine ispitanica, $\mathrm{p}=0.13$.

Na pitanje; "Mislite li da Vas je medicinska sestra na tečaju pripreme trudnice za porod mogla bolje informirati o nekim situacijama koje Vas očekuju tijekom poroda?", 42 ispitanice (52\%) smatraju da ih je sestra mogla malo bolje informirati, dok je 38 ispitanica (48\%) odgovorilo negativno.

U ocjeni je li medicinska sestra koja je bila član tima mogla više informirati pacijentice nije bilo statistički značajne razlike $(p=0,57)$ kada se usporede odgovori ispitanica koje su rodile carskim rezom u odnosu na ispitanice koje su rodile vaginalnim putem.

\subsection{Rezultati procjene komplikacija nakon poroda}

Na pitanje: "Nakon porođaja imali ste poteškoća prilikom stavljanja novorođenčeta u položaj adekvatan za dojenje?", 43 ispitanice koje su prošle trudnički tečaj odgovorile su da su imale problema (54\%), a $37(46 \%)$ ispitanica reklo je da nisu imale problema.

Nije bilo razlika u odgovorima o poteškoćama u stavljanju novorođenčeta u položaj za dojenje između babinjača koje su rodile carskim rezom u odnosu na ostale koje su rodile vaginalno $(p=0,26)$.

Na pitanje " Jeste li imali poteškoća kod dojenja, u smislu da novorođenče dobro ne obuhvaća bradavicu?" 52 ispitanice rekle su da su imale problema (65\%), a 28 njih je reklo da nije imalo problema (35\%). Prema rezultatima jednako su imale problema i babinjače koje su rodile carskim rezom kao i babinjače koje su rodile vaginalno $(p=0,77)$.

Na pitanje jesu li se snašle u prematanju novorođenčeta, 72 babinjače rekle su da su se snašle (90\%), a 8 ih je zaokružilo ne (10\%). Nije bilo razlike u odgovorima na pitanje jesu li se snašle u prematanju novorođenčeta kada se usporede odgovori ispitanica koje su rodile carskim rezom u odnosu na ispitanice koje su rodile vaginalnim putem $(p=10)$.

Na pitanje "Jeste li uspješno prvi put premotali novorođenče?", 66 ispitanica zaokružilo je da (82\%), a 14 ispitanica zaokružilo je ne (18\%). Nije bilo statistički značajne razlike u ocjeni snalaženja u prematanju $(p=0,21)$.

Nije bilo statistički značajne razlike u snalaženju prilikom prvog prematanja između babinjača koje su rodile carskim rezom $u$ odnosu na babinjače koje su rodile vaginalno $(p=$ $0,21)$. 
TABLICA [7] Distribucija odgovora na pitanja o procjeni komplikacija poslije poroda

\begin{tabular}{lcc}
\hline Pitanja o procjeni komplikacija nakon poroda & & \\
\cline { 2 - 3 } & $\begin{array}{c}\text { ispitanice koje su rodile } \\
\text { vaginalno } \\
\text { DA/ NE }\end{array}$ & $\begin{array}{c}\text { ispitanice koje su rodile } \\
\text { carskim rezom } \\
\text { DA/ NE }\end{array}$ \\
\hline $\begin{array}{l}\text { Nakon porođaja imali ste poteškoća prilikom stavljanja } \\
\text { novorođenčeta u položaj adekvatan za dojenje? }\end{array}$ & $11 / 5$ & $32 / 32$ \\
\hline $\begin{array}{l}\text { Jeste li imali poteškoća kod dojenja, u smislu } \\
\text { da novorođenče dobro ne obuhvaća bradavicu? }\end{array}$ & $11 / 5$ & $41 / 23$ \\
\hline Jeste li se snašli u prematanju novorođenčeta? & $15 / 1$ & $57 / 7$ \\
\hline $\begin{array}{l}\text { Jeste li uspješno prvi puta premotali novorođenče? } \\
\text { Mislite li da Vas je medicinska sestra na tečaju pripreme trudnice za } \\
\text { porod mogla bolje informirati o nekim situacijama koje Vas očekuju } \\
\text { tijekom poroda? }\end{array}$ & $12 / 4$ & $57 / 7$ \\
\hline
\end{tabular}

\subsection{Rezultati ispitivanja babinjača koje nisu pohađale trudnički tečaj}

Trudnički tečaj nije pohađalo 70 ispitanica (47\%). Od navedenog broja, njih 10 (14\%) rodilo je carskim rezom, a 60 (86\%) vaginalnim putem.

Na pitanje je li im nedostajao tečaj pripreme za porod najveći broj ispitanica (40\%) zaokružilo je srednju tvrdnju da se niti slaže, niti se ne slaže, $20 \%$ babinjača se uopće ili uglavnom ne slaže, $36 \%$ in se uglavnom slaže, a samo ih se $4 \%$ u potpunosti slaže.

U procjeni je li im nedostajao tečaj za trudnice u snalaženju nakon poroda prosječna ocjena koju su dale babinjače koje nisu prošle tečaj iznosila je 3,2 (1-5). Nije bilo razlike između ispitanica koje su rodile carskim rezom u odnosu na ispitanice koje su rodile vaginalnim putem $(p=0,19)$.

TABLICA [8] Odgovori ispitanica na pitanje je li im nedostajao tečaj za trudnice

\begin{tabular}{lcc}
\hline \multirow{2}{*}{$\begin{array}{l}\text { Nedostajala Vam je priprema za } \\
\text { porođaj putem tečaja pripreme }\end{array}$} & \multicolumn{2}{c}{ Ispitanice } \\
\cline { 2 - 3 } trudnice za porođaj & frekvencija & postotak \\
\hline uopće se ne slažem & 9 & 13 \\
\hline uglavnom se ne slažem & 5 & 7 \\
\hline niti se slažem, niti se ne slažem & 28 & 40 \\
\hline uglavnom se slažem & 25 & 36 \\
\hline u potpunosti se slažem & 3 & 4 \\
\hline Ukupno/Total & 70 & 100 \\
\hline
\end{tabular}

Na pitanje na koji su se način pripremale za porođaj ispitanice su navodile različite izvore. Uz TV i radio nije se pripremala niti jedna, internet kao izvor informacija koristilo je njih 65 , knjige i priručnike koristilo je njih 65 , te ostale izvore njih 30.
TABlica [9] Način na koji su ispitanice prikupile informacije o porodu

\begin{tabular}{|c|c|c|}
\hline \multirow{2}{*}{$\begin{array}{l}\text { Na koji ste se način } \\
\text { pripremali za porođaj }\end{array}$} & \multicolumn{2}{|l|}{ Ispitanice } \\
\hline & frekvencija & postotak \\
\hline mediji (TV, radio) & 0 & 0 \\
\hline internet & 65 & 93 \\
\hline knjige, priručnici, katalozi & 65 & 93 \\
\hline nešto drugo & 30 & 43 \\
\hline
\end{tabular}

\section{Rasprava / Discussion}

Rezultati istraživanja provedenog na Klinici za ginekologiju i porodništvo Kliničke bolnice „Sveti Duh“ na 150 ispitanica pokazuju da je najveći broj žena, njih 39\% bilo u starosnoj dobi od 31 do 35 godina starosti.

Nadalje, vidljivo je da najveći broj ispitanica ima srednji stupanj naobrazbe, njih $46 \%$ što se poklapa s posljednjim popisom stanovništva iz 2011. godine, prema kojem $42,5 \%$ stanovništva u RH ima srednji stupanj naobrazbe.

Većina ispitanica rađale su prvi put, njih čak $48 \%$, slijede ispitanice koje rađaju drugi puta, njih $35 \%$. Više od četvero djece nije imala niti jedna ispitanica.

U odnosu stavova o stupnju korisnosti tečaja za porod, $26 \%$ ispitanica dalo je najveću ocjenu, a $50 \%$ ispitanica uglavnom se slaže da su informacije koje su usvojile bile korisne za tijek poroda. Pri usvajanju navedenih rezultata, potrebno je usvojiti slijedeću znanstveno verificiranu činjenicu, i to: stav je mentalna spremnost, stečena individualnim iskustvom, koja vrši direktivni ili dinamički utjecaj na reagiranje pojedinca na objekte i situacije s kojima dolazi u dodir, odnosno stav je psihološka tendencija vrednovanjem nekog objekta s određenim stupnjem odobravanja ili ne odobravanja [5]. Jednom usvojeni stavovi pokazuju tendenciju da se u toku vremena petrificiraju, tj. da postanu otporni na pokušaje mijenjanja i modificiranja [6]. 
Prosječna ocjena korisnosti usvojenih informacija iznosi $3,93 \%$ što ukazuje na potrebu daljnjeg povečanja stupnja edukacije predavača.

Na pitanje o korisnosti stručnog tečaja [7] za stjecanje vještina njege novorođenčeta prosječna ocjena iznosi 3,72. Može se zaključiti da je potrebno daljnje povečanje stupnja kvalitete programa tečaja. Ovo se posebno odnosi na medicinske sestre-primalje. Potrebno je povećati stupanj edukacije MS-a za svrhe svakodnevnog obilsaka. Za tu vrstu edukacije uglavnom je zadužena medicinska sestra-primalja. Ona razgovara s babinjačama i savjetuje o njezi novorođenčeta i dojenju.

Potrebne informacije o tijeku trudnoće i poroda potrebno je verificiranim edukacijsko-metodološkim metodama detaljno provjeriti te ih prilagoditi kako bi ih trudnice jednostavno usvojile [8].

Rezultati istraživanja pokazuju da $98 \%$ žena želi dojiti, ali da ih samo $44 \%$ ne očekuje probleme u vezi sa dojenjem. To pak ukazuje da je potreban cjelovit i kontinuiran pristup u edukaciji trudnica o prednostima dojenja. Naime, vrlo često žene nisu motivirane za dojenje [9]. Boje se nastanka prekomjerne bolnosti, nastanka ragada, postoji strah da je dijete gladno i da stoga može izgubiti na težini zbog čega postoji mogućnost duljeg ostanka u bolnici i sl. Medicinske sestreprimalje imaju značajnu ulogu u smanjivanju obima opisane problematike, te moraju preuzeti odgovornost u provođenju metoda prevencije i zbrinjavanju nastalih neželjinih komplikacija koje se pojavljuju u procesu dojenja [10].

Prema dobivenim rezultatima istraživanja vidljivo je da je stupanj educiranosti medicinskih sestara ocijenjen prosjekom 4,37, što je zadovoljavajući rezultat.

Za medicinsku sestru koja je dio edukacijskog tima koji učestvuje u provođenju programa tečaja za trudnice, vidljivo je da $52 \%$ ispitanica smatra da ih je medicinska sestra mogla bolje informirati o nekim situacijama koje ih očekuju tijekom poroda. Stoga je potrebno povećati stupanj pozitivnog odnosa, tzv. učinkovite komunikacije, te povećati mogućnosti usvajanja/učenja o indikacijama i tijeku provođenja sestrinskih postupaka za rodilju i babinjaču [11].

Od ukupnog broja ispitanica, 54\% navelo je problem sa stavljanjem novorođenčeta u položaj adekvatan za dojenje, a $46 \%$ nije. Čak $65 \%$ ispitanica imalo je problema kod obuhvačanja bradavica prilikom dojenja. Možemo zaključiti da trudnice nisu dobile u dostatnom obimu potrebne informacije, usprkos pohađanja trudničkog tečaja, ali ni od medicinske sestre-primalje, zadužena za obilazak babinjače $i$ provođenje svakodnevne kontinuirane edukacije.

Prema rezultatima polaznice tečaja zadovoljavajuće su usvojile i ocijenile stupanj znanja potreban za provođenje odgovarajućeg prematanja novorođenčeta.

Značajan obim trudnica nije pohađao pripremni tečaj (47\%), a prema rezultatima iste su prihvaćale potrebna znanja uporabom interneta, knjiga i priručnika.

$\mathrm{U}$ odnosu na rezultate provedenog istraživanja postoje značajne razlike u odnosu na istraživanje provedeno 2007. godine, koje iskazuje da $16 \%$ žena koje su prvi puta trud- ne i $13 \%$ višerotki navodi kao najznačajniji izvor informacija uporabu interneta [12]. Kao prednost interneta ispitanice navode mogućnost da svaku informaciju pogledaju neograničen broj puta i u bilo koje doba [12].

\section{Zaključak/ Conclusion}

Prema dobivenim rezultatima može se zaključiti da značajan broj trudnica ne polazi trudničke tečajeve, da su stavovi ispitanica o stupnju koristi tečaja su značajno pozitivni, da velik broj babinjača ima poteškoća prilikom stavljanja novorođenčeta u adekvatan položaj za dojenje.

Priprema trudnice za porođaj znanstveno je verificirana. Za provođenje iste potrebno je kontinuirano povećanje stupnja kvalitete, metoda, organizacija patronažne zdravstvene djelatnosti, rodilišta te povečanje trajne komunikacije između navedenih zdravstvenih strukovnosti. Nadalje, potrebna je trajna edukacija medicinskih sestara-primalja, kako bi one mogle poboljšati pripremljenost trudnica za porođaj. Posebnu pažnju treba posvetiti trajnoj edukaciji o učinkovitosti dojenja, i to posebice od zdravstvenih djelatnika koji obavljaju svakodnevne radne zadatke u sustavu primarne zdravstvene zaštite, ali i u bolničkim zdravstvenim ustanovama (rodilište).

Preporučljivo je da se edukacija trudnica u budućnosti zasniva na individualnoj interakciji odgovarajuće educiranih zdravstvenih djelatnika i trudnice.

\section{Authors declare no conflict of interest}

\section{Literatura/references}

[1] Kuvačić I, Kurjak A,Đelmiš J. i sur, Porodništvo, Medicinska naklada, Zagreb, 2009, str.68-72

[2] Županić M, Turuk V, Ćurik D, Bertić LJ. Evaluacija provođenja trudničkih tečajeva tijekom 2000-2012.god., Zdravstveno veleučilište Zagreb, Dom zdravlja Zagreb-Centar-patronažna djelatnost, Dom zdravlja Bjelovarsko-bilogorske županije, Zagreb, 2012.

[3] A. Dražančić i sur. Porodništvo, Školska knjiga, Zagreb, 1994, str.162188.

[4] Kunina B, Ivančić M, Finderle B. Vaginalni porođaj. Primaljski vjesnik 2012; 12:34-40.

[5] Zvonarević M, Stavovi M. Socijalna psihologija, Školska knjiga, Zagreb, 1976, str. 245-252.

[6] Pennington CD. Stavovi i promjene stava. Published at Pennington CD, Osnove socijalne psihologije, Naklada Slap, Jastrebarsko, 1997, str. 82-102.

[7] Kurjak A, Latin V. Ususret roditeljstvu, Tonimir, Varaždinske toplice, 1998, str. 479-508.

[8] Hodnett ED, Gates S, Hofmeyr GY, Skala C. Continous support for women during childbirth Cochrane Database Syst Rev, 2007; (3): CD003766

[9] Mujkić A, Vuletić G. Znanje i stavovi rodilja o dojenju, Acta Medica Croatica. 2004;58 : 37-41

[10] Adeyemo F, Oyadrian G, Ljedimma M, Akinlabi B, Adewale A. Perception of pregnant women towards midwivwe:attitude and practice during child delivery in health institutions in Ogbomoso, Epidemiology Biostatistics and Public Health, South-West, Nigeria, 2014,11 (2).

[11] K. MacKinnon, M. McIntyre, Quance J. The Meaning of the Nurse's Presence During Childbirth. Clinical research. 2005. Volume 34, Number 1.28-36

[12] Romano A. Chaning Landscape: Implications of Pregnant Women's Internet Use for Childbirth Educators. The Journal of Education. 2007; 16(4); 18-24 